\title{
Arte documental y exceso de realidad
}

\author{
Pablo Martínez Zárate \\ Artista audiovisual e Investigador \\ (Laboratorio Iberoamericano de Documental)
}

\section{Referencia de este artículo}

Martínez Zárate, Pablo (2020). Arte documental y exceso de realidad. adComunica. Revista Científica del Estrategias, Tendencias e Innovación en Comunicación, (19), 295-298. DOI: http://dx.doi.org/10.6035/2174-0992.2020.19.17.

Vivimos inmersos en lo real. Tejemos lo real a diario y así la realidad es un telar siempre inacabado. La realidad es tejido de experiencia compartida, de existencia en relación, de horizontes de mundo. La realidad está en fuga perpetua: «La realidad huye», dice Trinh Minh-Ha, «la realidad niega la realidad». Nosotros corremos detrás de ella. La imaginamos otra, máquina en mano.

Los medios de expresión, en su sentido más amplio, son el terreno donde se debaten los horizontes de lo real. Donde se tejen y destejen los ropajes del tiempo humano. Los medios para ser humanos, solos y acompañados, con lo otro, humano y no-humano. Los medios son materia e idea. Son vehículos de formas, agencias formativas, son in-formación, comunicación de relaciones. Cada soporte tiene su identidad espacial y temporal, sus modos de interrelación con el gran tejido mediático. En estos patrones emergen los estándares, las convenciones, los medios normativos y los esquemas de valor, los modelos de mundo, las revoluciones, el archivo y otras tantas historias que nos dejan ser humanos.

El arte es exceso de realidad. Todo arte mediático, al situarse en el desafío de los lenguajes y soportes, habita este umbral de lo real, siempre vivo, terreno fértil para imaginar otras formas de existencia en común. En lo personal, asumo mi prácti- 
ca en medios desde dos lugares: sitio de imaginación y sitio de enunciación. La enunciación es la imaginación manifiesta, la expresión de una experiencia. Implica el uso de medios para la puesta en relación (en público) de un proceso imaginativo, la articulación técnica de ideas que voy desarrollando con el tiempo, solo o acompañado. Todo arte mediático es un arte textual. Un arte del tejido (texo lat. tejer). Conjugación de soportes y, por lo tanto, tiempos y espacios diversos.

La noción de arte documental ha acompañado mis investigaciones artísticas y académicas. No tanto por cuestiones de estilo o género como por las metodologías implementadas en la resolución de proyectos. Por un lado están la postura discursiva y la revisión de temas de interés, por otro los soportes y lenguajes aplicados, los registros de realidad con los que estoy trabajando.

La relación con el archivo es extensiva e intensiva, en tanto sitio de consulta y sitio de intervención, impacta los dos niveles — técnico y temático- que son la base de la enunciación. La intervención del archivo sucede por la manipulación de documentos y la producción de nuevas inscripciones. La intervención del archivo sucede también cuando inventamos relaciones entre documentos existentes, cuando producimos arquitecturas - posibles - de sentido. El arte documental entiende al archivo como un sitio de acontecimiento, un sitio donde, siguiendo a Badiou, puede acontecer lo múltiple.

La exploración de lo real — desde un arte documental como aquí lo entiendo- parte del supuesto que hay dimensiones de lo real — de la experiencia mediada - que desconocemos, algunas que nunca llegaremos a conocer. Al localizar esta limitante, confiando plenamente en la intuición, se inaugura la necesidad de desarrollar formas alternativas de conocimiento - y exploración y expresión- de y sobre y a través y a un costado de la realidad, especialmente cuando la realidad está marcada por la crisis y la convulsión, cuando vivimos bajo lo que Hito Steyerl llamó «exceso de mundo».

Si hay dimensiones de lo real que nos son desconocidas, hay dimensiones de experiencia imaginables y cognoscibles, aunque no todas puedan ser documentadas. Siempre hay un límite a la inscripción de la experiencia. Una selección, un poder, en la memoria. Asimismo, no toda realidad puede ser narrada. Es el dilema eterno de la narración, toda poética lidia con esta inefabilidad de la experiencia humana. Los proyectos artísticos que he desarrollado tienen un horizonte y una realidad marcada por los recursos y la capacidad de las personas involucradas. Intento navegar entre la realidad del proyecto y su potencial mediante la escritura y el montaje como vértebras de la investigación técnica y temática. Por supuesto, hay investigaciones madre que preceden y suceden a proyectos concretos, que más bien los vinculan y van dando sentido a todo un cuerpo de obra.

Por otro lado, el dilema del artista mediático deviene en una lucha contra ese exceso de mundo, ya que siempre participa de un modo u otro del mismo circu- 
lacionismo excesivo apuntado por Steyerl. No sorprende que la práctica crítica en medios esté vinculada con la investigación del archivo como sitio de experiencia (y, por lo tanto, de conocimiento y creación de comunidad). No nada más mediante el trabajo con desechos sonoros y visuales, sino también con la relocalización de las máquinas que van quedando atrás en la carrera circense de la tecnología, el arte documental se propone una reinvención del relato histórico, de sus modos de enunciación. Con cierta vocación arqueológica, el arte documental es por definición una práctica expandida, excesiva.

Mi producción artística se ha desarrollado de la mano de una práctica pedagógica de corte crítico, inspirada principalmente en la tradición latinoamericana, que atraviesa no solamente el ámbito de lo educativo, sino sus cruces con lo comunicacional y lo artístico. La investigación pedagógica y la investigación artística, en el esquema de trabajo que he desarrollado en los últimos años, se han definido mutuamente según los entornos de enseñanza y los procesos en cuestión.

Después de más de una década de producir impresos, películas, web documentales, video instalaciones y piezas interactivas ${ }^{1}$, he desarrollado algunos apuntes metodológicos para la creación artística que recurre a distintos medios. Buscan un entendimiento del diseño de medios en función de los fines discursivos de cada proyecto y situación, siendo las incursiones temáticas indisolubles de la experimentación técnica y las formas posibles de comunicar los temas de interés. Es un modelo basado en la búsqueda, detección e intervención de relaciones a nivel técnico y temático, para el diseño e implementación de estrategias expresivas siempre en diálogo con un contexto cambiante.

En lo temático se inscribe lo discursivo o particular de cada proyecto, mientras lo técnico se relaciona más con la ocupación de los recursos. La técnica revela nuestra ocupación del territorio, define la ocupación del artista. Contrario a lo que se podría pensar, lo técnico suele ser mucho más político que lo temático. Lo técnico es el campo rector al hablar de una postura crítica del artista frente al entorno mediático contemporáneo; tema de temas, donde se desenvuelve toda acción del arte documental, que implica aquellos modos en que encarnamos la enunciación desde una técnica — techné - siempre situada, susceptible de inscripción y narración, en relación con otros medios y otros límites de lo imaginable, de lo habitable. De ahí el potencial disruptivo del arte documental en medios múltiples, su adaptabilidad. De ahí también su gran peso como agente inmerso en la narración histórica. ¿Cómo usamos la tecnología para expresar lo que queremos expresar, cómo ejercemos los recursos al alcance apuntando siempre a nuestra mejor capa-

\footnotetext{
1 Un elemento que he comenzado a valorar recientemente, teniendo un cuerpo de obra de una década en soportes con requisitos técnicos muy específicos (piezas web y material fotoquímico que en muchas ocasiones forman parte de una misma pieza), es la preservación y conservación de mi propia producción. Refuerza la importancia de pensar al archivo. Al trabajar en soportes múltiples, la posibilidad de preservar y conservar el patrimonio audiovisual expandido, presenta varios retos técnicos que aunque no hay espacio aquí para tratar, son importantes cuando pensamos en preservación del patrimonio artístico y también en el archivo de producción de un estudio de artista.
} 
cidad? ¿Cómo preservamos estas versiones alternativas del relato histórico? O, según advertía uno de los primeros intelectuales de y sobre Internet, sin duda un excéntrico: cuando accionamos una máquina cualquiera, ya sea para crear una obra de arte o para mandar un mensaje de texto, ¿en qué tipo de persona nos convertimos? ¿Qué realidad tejemos? 